\title{
REMEDIAÇÃO DE SOLOS CONTAMINADOS POR PROCESSOS FENTON: UMA REVISÃO CRÍTICA
}

\author{
Alecsandra dos Santos, Graziela da Silva Costa e Patricio Peralta-Zamora* \\ Departamento de Química, Universidade Federal do Paraná, CP 19081, 81531-980 Curitiba - PR, Brasil
}

Recebido em 20/05/2016; aceito em 27/09/2016; publicado na web em 02/11/2016

\begin{abstract}
FENTON REMEDIATION OF CONTAMINATED SOILS: A CRITICAL REVIEW. The remediation of contaminated soils is probably one of the biggest environmental challenges, mainly due to the complex dynamics of the pollutants in this medium. Among a variety of treatment alternatives proposed for the in-situ remediation of contaminated soils, Fenton processes appear as the most cost-effective, particularly when catalyzed by native iron oxides. However, both the efficiency of the Fenton process and its effect on the treated soil, are largely dependent of the treatment conditions and the main characteristics of the soil, which implies the nonexistence of universal procedures. In this work, the use of Fenton processes in soil remediation routines is critically evaluated, emphasizing aspects related to the degradation efficiency, the influence of the soil properties, the degradation mechanisms and the impacts on the treated soil.
\end{abstract}

Keywords: soil remediation; Fenton process; mineral iron.

\section{INTRODUÇÃO}

A remediação de solos contaminados provavelmente representa um dos maiores desafios na área ambiental, não apenas em função da usual complexidade das matrizes de solo, mas principalmente em razão da complexa dinâmica dos poluentes nos ambientes contaminados. ${ }^{1}$ Em razão desta complexidade e da elevada frequência com que episódios de contaminação do solo são verificados, muitas tecnologias de tratamento tem sido propostas nas últimas décadas, incluindo alternativas simples de tratamento in-situ, como sistemas fundamentados em atenuação natural e sistemas onerosos e complexos fundamentados em processos ex-situ, como tratamento térmico em plasma.

Dentro do contexto das novas tecnologias é possível destacar os processos de oxidação avançada (POAs), como os processos Fenton, que têm demonstrado elevada eficiência de degradação frente a inúmeros poluentes ambientais tóxicos e recalcitrantes, ${ }^{2}$ inclusive em matrizes de solo. ${ }^{3}$ Particularmente relevante se mostram os estudos de remediação de solos contaminados por hidrocarbonetos derivados de petróleo, os quais, apresentando toxicidade para a população microbiana do solo, dificilmente podem ser degradados por processos biológicos naturais. ${ }^{1}$ Nos últimos anos, também destacam importantes aplicações do processo Fenton na remediação de solos contaminados por hidrocarbonetos policíclicos aromáticos, poluentes que se mostram resistentes à degradação microbiana e que são considerados prioritários pela agência de proteção ambiental dos Estados Unidos.

Em geral, a eficiência de degradação dos processos Fenton é dependente de algumas características do solo, natureza e concentração das formas minerais de ferro e da concentração de matéria orgânica. Assim, não existem condições universais que permitam a mesma eficiência de degradação em solos de natureza diferente. Por outro lado, as reações Fenton podem impactar de forma negativa a qualidade do solo submetido a tratamento e do entorno, destacando a degradação da matéria orgânica e de consórcios microbianos e a lixiviação de metais e de subprodutos de degradação.

Em função destas últimas observações, o presente trabalho objetiva a realização de uma análise crítica sobre a aplicação de processos Fenton na remediação de solos contaminados por derivados

*e-mail: zamora@ufpr.br de petróleo, enfatizando, não apenas os aspectos relacionados com a eficiência de degradação, mas também os impactos negativos que a sua aplicação pode envolver.

\section{CONTAMINAÇÃO DO SOLO POR DERIVADOS DE PETRÓLEO}

Nas últimas décadas a poluição causada por derivados de petróleo tem sido bastante frequente, principalmente em decorrência de vazamentos, derrames e acidentes durante a exploração, refinamento, transporte e operações de armazenamento e distribuição, ${ }^{4}$ o que representa uma fonte contínua de contaminação dos solos e dos sistemas hídricos, com reflexos negativos nos ecossistemas envolvidos e na saúde humana. ${ }^{5}$

Geralmente, as espécies químicas que exigem maior preocupação ambiental nos episódios de contaminação do solo por derivados de petróleo são benzeno, tolueno, etilbenzeno e os isômeros do xileno. Estas espécies, coletivamente chamadas de BTEXs, correspondem à fração mais tóxica e de maior mobilidade no solo,,${ }^{4,6}$ sendo preferencialmente monitoradas nos casos de contaminação e durante os processos de remediação. Estes contaminantes são considerados substâncias perigosas, por serem depressores do sistema nervoso central e por causarem leucemia quando em exposições crônicas. ${ }^{7}$ Além dos BTEXs, outros grupos de hidrocarbonetos podem ser monitorados nos casos de contaminação, incluindo hidrocarbonetos totais de petróleo (HTPs), hidrocarbonetos policíclicos aromáticos (HPAs) e compostos orgânicos voláteis (COVs), todos de reconhecida toxicidade e persistência no meio ambiente. ${ }^{4}$

A contaminação do solo por compostos orgânicos é um processo complexo, comandado por diversos fatores que dependem da natureza química dos contaminantes e das propriedades físico-químicas do solo. Assim, no caso particular dos hidrocarbonetos de petróleo, processos de volatilização favorecem a eliminação das espécies mais voláteis, processos de sorção comandam a retenção de espécies mais hidrofóbicas, enquanto que a solubilização favorece a lixiviação de espécies de maior polaridade relativa (ver ilustração em Figura 1).

No solo, os hidrocarbonetos alifáticos podem ser parcial ou totalmente degradados, graças à ação de consórcios microbianos formados por bactérias e fungos. Por sua vez, espécies aromáticas mostram maior resistência frente a processos de bioatenuação natural, 


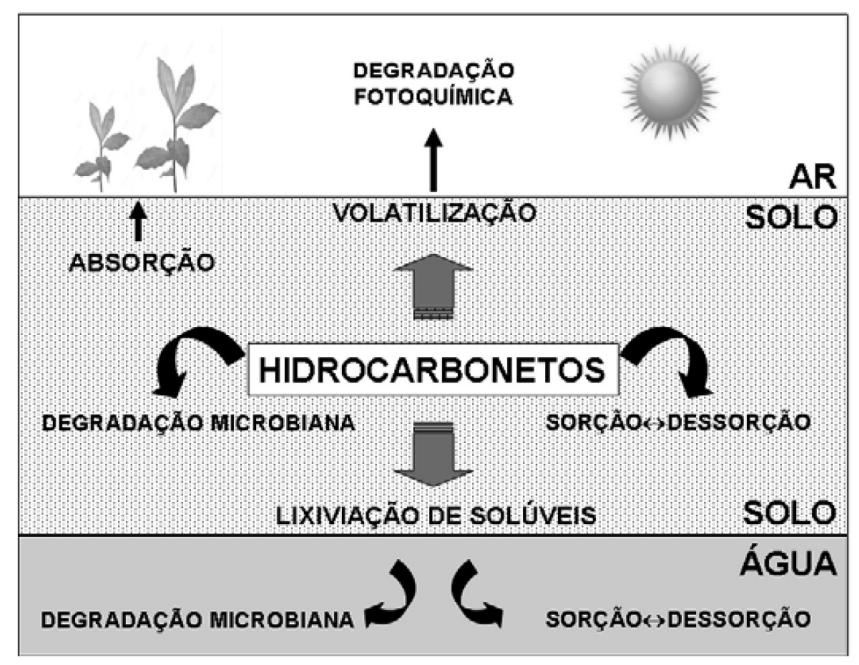

Figura 1. Representação esquemática da dinâmica dos hidrocarbonetos no solo contaminado

principalmente quando na presença de etanol, em razão da degradação preferencial deste aditivo. ${ }^{8}$

\section{Remediação de solos contaminados}

A remediação de solos contaminados por compostos orgânicos é um desafio complexo, principalmente em razão da solubilidade relativamente baixa dos poluentes, da sua retenção por adsorção nos componentes do solo e do limitado acesso dos micro-organismos para ocorrência de processos de biodegradação. ${ }^{5,9}$ Em decorrência destas características, processos de bioatenuação natural apresentam escassa aplicação, o que tem servido de incentivo para a proposta de vários procedimentos alternativos, incluindo sistemas de remediação in-situ, caracterizados pelo tratamento no próprio local da contaminação, e sistemas ex-situ, em que o solo contaminado é previamente removido do local. ${ }^{10}$ Uma ilustração que representa algumas alternativas de tratamento in-situ e ex-situ é apresentada na Figura 2.
Em geral, tratamentos ex-situ permitem eficiente e uniforme remediação dos solos contaminados, em tempos relativamente curtos. Em contrapartida, a necessidade de remover e transportar o solo contaminado até a unidade de tratamento encarece o processo, o que representa uma das grandes desvantagens deste tipo de proposta. ${ }^{11}$ Várias técnicas ex-situ têm sido propostas para a remediação de solos contaminados por poluentes orgânicos, recorrendo-se a processos biológicos, físicos e químicos. Dentre os processos biológicos se destacam sistemas de biopilhas e landfarming, ${ }^{12}$ enquanto que dentre os processos físicos se destacam processos de dessorção térmica. ${ }^{13}$ Os processos químicos oferecem uma grande gama de alternativas, envolvendo processos simples, como extração dos contaminantes por lavagem, ${ }^{14}$ ou de maior complexidade, como sistemas de oxidação química mediada por agentes como peróxido de hidrogênio, ozônio e permanganato. ${ }^{15}$

Por outro lado, os processos in-situ costumam apresentar um menor custo de tratamento, em razão de não haver a necessidade de remoção e transporte. Contudo, características como longo período de tratamento e não uniformidade na eficiência de remediação representam importantes desvantagens deste tipo de alternativa. Alternativas para tratamento in-situ são usualmente fundamentadas em processos físicos que objetivam a remoção de espécies voláteis, como extração de vapor ${ }^{16}$ e injeção de ar (soil venting ou air sparging), ${ }^{17}$ ou em processos biológicos fundamentados em atenuação natural, com ou sem estimulação. ${ }^{18}$ Processos químicos costumam envolver sistemas de extração por lavagem, usualmente utilizando surfactantes, ${ }^{19}$ e processos de oxidação fundamentados no uso de agentes como persulfato. ${ }^{20}$

Seja em função do alto custo dos sistemas ex-situ, do caráter não destrutivo dos processos físicos aplicados in-situ ou da extrema vagarosidade dos sistemas de bioatenuação, principalmente na degradação de poluentes resistentes, a necessidade de novas alternativas de tratamento se mostra evidente. Dentro do contexto das novas tecnologias é possível destacar os processos de oxidação avançada fundamentados em processos Fenton, que têm demonstrado elevada eficiência de degradação frente a inúmeros poluentes ambientais tóxicos e recalcitrantes.

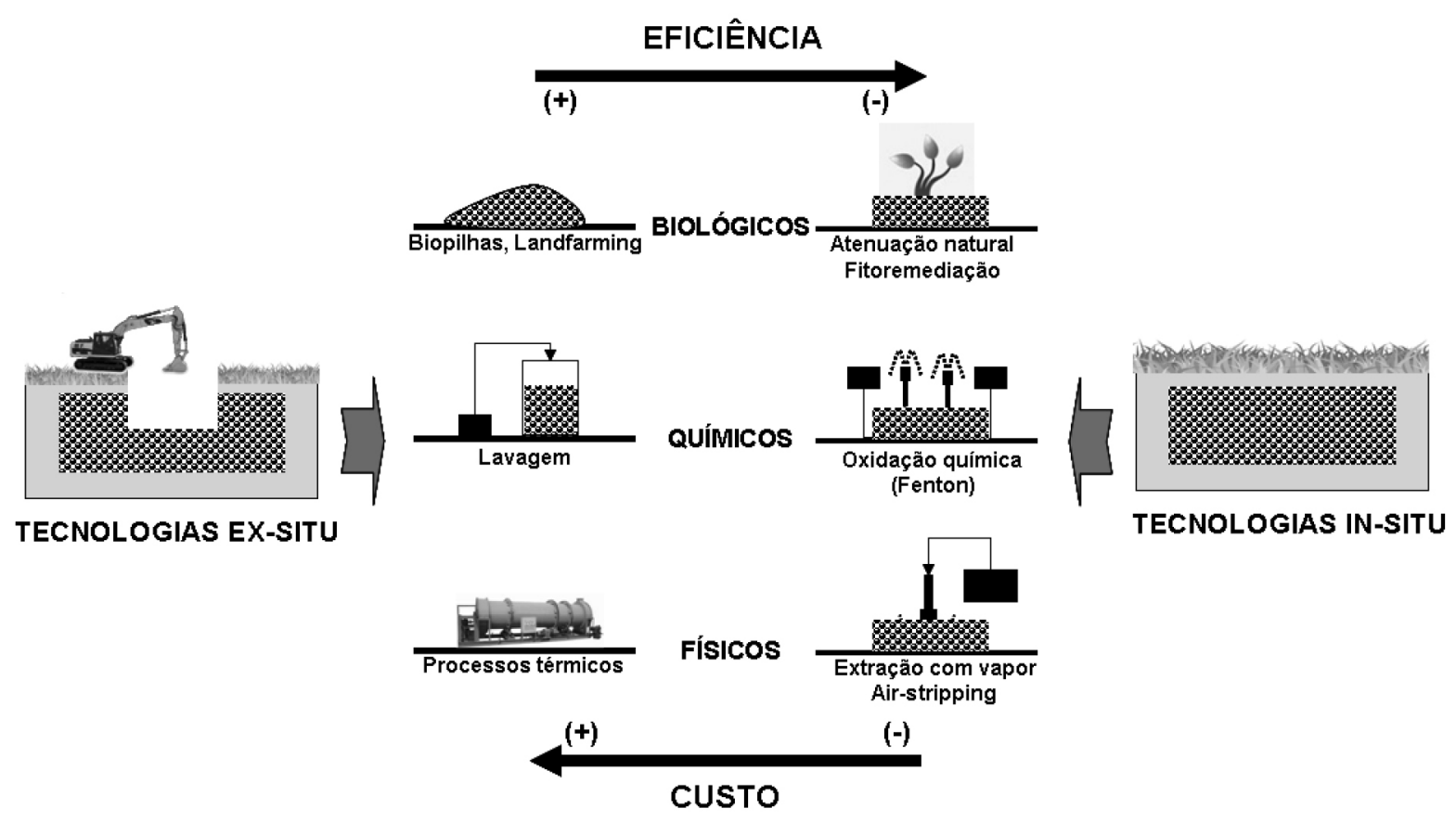

Figura 2. Ilustração de sistemas in-situ e ex-situ para tratamento de solos contaminados 


\section{PROCESSOS DE OXIDAÇÃO AVANÇADA (POA $\left.{ }_{\mathrm{s}}\right)$}

Os POAs são fundamentados na geração de espécies radicalares, principalmente radical hidroxila $(\mathrm{OH} \bullet)$, que apresenta uma elevada capacidade de degradação oxidativa e reage com uma extensa variedade de compostos orgânicos promovendo, na maioria dos casos, a sua completa mineralização. ${ }^{21}$

Tratam-se de versáteis alternativas de tratamento, em função do radical hidroxila viabilizar a substituição eletrofílica em compostos aromáticos, a adição eletrofílica em alcenos e a abstração de hidrogênio em alcanos. ${ }^{3} \mathrm{~A}$ versatilidade dos POAs também é reforçada pelo fato de que os radicais hidroxila podem ser gerados por diferentes processos homogêneos e heterogêneos, irradiados ou não, normalmente envolvendo o uso de oxidantes relativamente econômicos, como ozônio, peróxido de hidrogênio $\left(\mathrm{H}_{2} \mathrm{O}_{2}\right)$ e reagente de Fenton, entre outros. ${ }^{21,22}$

\section{Processos Fenton}

O processo Fenton convencional baseia-se na geração de radicais hidroxila, a partir da decomposição de peróxido de hidrogênio catalisada por íons ferrosos (Equação 1). ${ }^{22,23}$ As reações Fenton também podem ser catalisadas por íons férricos, dando lugar a processos denominados Fenton-like. Embora cineticamente mais desfavorecida, esta reação leva à geração de radical hidroperoxila $\left(\mathrm{HO}_{2}{ }^{\circ}\right)$ e $\mathrm{Fe}^{2+}$ (Equação 2), espécie, esta última, que desencadeia o processo Fenton tradicional representado na Equação $1 .{ }^{22-25}$ Assim, processos Fenton catalisados por $\mathrm{Fe}^{2+}$ se mostram mais eficientes na presença de baixas concentrações de peróxido, enquanto que processos mediados por $\mathrm{Fe}^{3+}$ são favorecidos com o uso de concentrações mais elevadas. ${ }^{3}$

$\mathrm{Fe}^{2+}+\mathrm{H}_{2} \mathrm{O}_{2} \rightarrow \mathrm{OH} \bullet+\mathrm{OH}^{-}+\mathrm{Fe}^{3+} \quad\left(\mathrm{K}=76,5 \mathrm{~L} \mathrm{~mol}^{-1} \mathrm{~s}^{-1}\right)$

$\mathrm{Fe}^{3+}+\mathrm{H}_{2} \mathrm{O}_{2} \rightarrow \mathrm{HO}_{2} \bullet+\mathrm{H}^{+}+\mathrm{Fe}^{2+} \quad\left(\mathrm{K}=0,001-0,01 \mathrm{~L} \mathrm{~mol}^{-1} \mathrm{~s}^{-1}\right)$

Dentre as principais vantagens dos processos Fenton é possível mencionar a elevada capacidade de degradação frente a inúmeros substratos considerados resistentes, a simplicidade operacional permitida pela ocorrência de reações em meio homogêneo e a baixa toxicidade dos reagentes envolvidos no processo.

\section{Processos Fenton aplicados na remediação de solos}

O emprego de reações Fenton para remediação de solos começou em 1990, quando Watts e colaboradores relataram a degradação de pentaclorofenol com o uso de peróxido de hidrogênio e sais ferrosos. ${ }^{26}$ Desde então, os processos Fenton vêm sendo amplamente empregados para a remediação de solos contaminados com diversos poluentes, particularmente hidrocarbonetos derivados de petróleo. 6,27,28

Em geral, o uso de formas solúveis de ferro (II) permite uma eficiente degradação de poluentes. Entretanto, as reações devem ser realizadas em meio ácido ( $\mathrm{pH} 2$ a 3), de maneira a se evitar a precipitação de óxidos férricos que apresentam menor capacidade de catálise ${ }^{3}$ e que tendem a reduzir a permeabilidade do solo. ${ }^{28}$ Desta forma, é usual o uso de soluções aquosas de ácido sulfúrico, que permitem manter as formas iônicas de ferro em solução, mas que podem causar severo impacto ambiental.

Por outro lado, o uso de ferro mineral aumenta a faixa operacional de $\mathrm{pH}$, o que permite tratamentos sem necessidade de alterar as condições naturais do solo. ${ }^{29}$ Adicionalmente, os óxidos férricos decompõem peróxido de hidrogênio de forma mais lenta, o que permite uma maior estabilidade e alcance do oxidante, favorecendo a degradação de contaminantes em zonas mais profundas. . $^{3,30}$

Processos Fenton fundamentados no uso de ferro mineral datam de 1991, ano em que Tyre, Watts e Muller ${ }^{31}$ demonstraram a excelente capacidade destas espécies como catalisadoras das reações de Fenton, observando uma elevada eficiência na decomposição do peróxido de hidrogênio e na concomitante degradação de poluentes. Nos últimos anos, inúmeros estudos relatam a remediação de solos contaminados por processos Fenton-like catalisados por formas minerais de ferro, incluindo goethita $(\mathrm{FeO}(\mathrm{OH}))$, hematita $\left(\mathrm{Fe}_{2} \mathrm{O}_{3}\right)$, magnetita $\left(\mathrm{Fe}_{3} \mathrm{O}_{4}\right)$ e pirita $\left(\mathrm{FeS}_{2}\right)$, dentre outras. ${ }^{32}$

\section{Processos Fenton catalisados por minerais de ferro}

O uso de ferro mineral como catalisador de processos Fenton tem sido abundantemente relatado na literatura, usualmente permitindo elevada eficiência na degradação de hidrocarbonetos associados à contaminação por combustíveis. Em 2002, por exemplo, Watts e colaboradores ${ }^{33}$ observaram uma maior eficiência das formas minerais de ferro na degradação de benzo(a)pireno, em relação a sistemas Fenton mediados por formas solúveis de $\mathrm{Fe}^{2+}$. Pereira, Marques e Pérez ${ }^{34}$ estudaram a remediação de solos argilosos contaminados por diesel, verificando uma elevada taxa de degradação dos processos Fenton catalisados pelas formas minerais de ferro (8\% de goethita e $5 \%$ de hematita), assim como nenhuma melhora significativa nos processos em que houve adição de íons $\mathrm{Fe}^{2+}$.

Estudos similares realizados por Xu e colaboradore ${ }^{28}$ e Romero e colaboradores ${ }^{35}$, envolvendo a remediação de solos contaminados por diesel e fenol, respectivamente, confirmam a pouca influência da adição de formas solúveis de ferro na eficiência de degradação dos processos Fenton aplicados em solos com elevado teor de ferro mineral, assim como a significativa melhora provocada pelo uso de maiores concentrações de peróxido de hidrogênio.

De maneira geral, dois tipos de mecanismo de reação são propostos para as reações Fenton catalisadas por minerais de ferro (ex. goethita, $\mathrm{Fe}^{\mathrm{III}} \mathrm{OOH}$ ). O primeiro, proposto por Haber e Weiss em $1934,{ }^{36}$ pressupõe a dissolução preliminar do mineral, favorecida em meio ácido, com formação de formas solúveis de Fe (III) que iniciam reações do tipo Fenton (Fenton-like Eq. 2). O segundo, proposto por Lin e Gurol em 1998, ${ }^{37}$ corresponde a uma sequência de reações heterogêneas que envolvem a complexação do peróxido de hidrogênio na superfície do mineral, a redução do $\mathrm{Fe}(\mathrm{III})$ a $\mathrm{Fe}(\mathrm{II})$ e a formação de radical hidroxila a partir de reações Fenton heterogêneas (Figura 3).
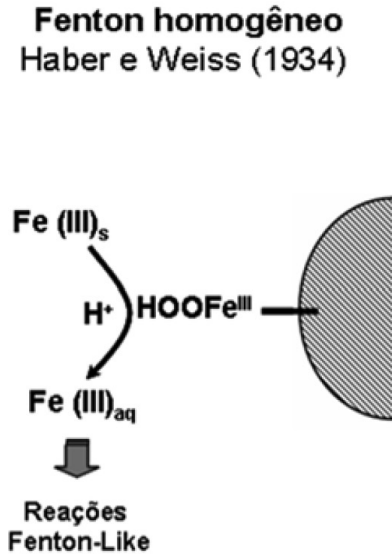

Fenton hetrogêneo Lin e Gurol (1998)
Figura 3. Representação de reações Fenton homogêneas e heterogênea catalisada por formas minerais de ferro

Em geral, estima-se que os dois tipos de mecanismos podem ocorrer simultaneamente em sistemas catalisados por ferro mineral. Entretanto, admite-se que a presença de minerais amorfos, como ferrihidrita $\left(\mathrm{Fe}_{10} \mathrm{O}_{14}(\mathrm{HO})_{2}\right)$, favorece a ocorrência de processos 
homogêneos, em razão da maior solubilização de ferro, enquanto que minerais cristalinos, como goethita, magnetita e hematita, promovem a catálise heterogênea, em razão da sua baixa solubilidade. ${ }^{38}$ Khan e Watts, ${ }^{39}$ por exemplo, estimaram que aproximadamente $94 \%$ da quantidade de percloroetileno é degradada por processos Fenton heterogêneos catalisados por goetita. Valores similares foram estimados por Chou e Huang ${ }^{40}$ em estudos envolvendo a remediação de solos contaminados por ácido benzóico.

$\mathrm{O}$ tipo de reação também é determinado pelo $\mathrm{pH}$ do sistema. Quando as reações são conduzidas em meio ácido (pH 3,0) a dissolução dos minerais é favorecida, o que também favorece a ocorrência de processos Fenton homogêneos. Em meio neutro, a concentração de ferro solúvel é muito baixa, o que sugere a formação de radicais hidroxila por processos heterogêneos catalisados na superfície dos minerais. ${ }^{41}$

Finalmente, é importante salientar que as espécies radicalares formadas pela decomposição do peróxido de hidrogênio também podem ser diferentes quando a reação é catalisada por ferro solúvel ou ferro mineral. Teel e colaboradores, por exemplo, ${ }^{42}$ estudaram a degradação de tricloroetileno por processos Fenton catalisados por íons $\mathrm{Fe}^{2+}$ e goethita em $\mathrm{pH}$ 3,0 e 7,0. Os estudos permitiram observar que em pH 3 a degradação mediada por $\mathrm{Fe}^{2+}$ é devida basicamente a ação de radical hidroxila, enquanto que na presença de goethita uma parcela da ordem de $15 \%$ da degradação é devida a outras espécies radicalares, como $\mathrm{O}_{2} \bullet^{-}$e $\mathrm{HO}_{2} \bullet$. Em pH 7, o uso de goethita permite uma eficiente degradação de tricloroetileno, praticamente na ausência de radical hidroxila.

\section{Fatores que influenciam a eficácia dos processos Fenton em solos}

De modo geral, a eficácia do processo Fenton depende principalmente da concentração dos reagentes $\left(\mathrm{Fe}^{2+} / \mathrm{Fe}^{3+} \mathrm{e} \mathrm{H}_{2} \mathrm{O}_{2}\right)$, parâmetros dos quais depende a efetividade global da reação, ${ }^{28}$ assim como de algumas características do solo, incluindo a forma mineral de ferro e a sua concentração, o teor de matéria orgânica e a presença de espécies inorgânicas.

A concentração dos reagentes é de fundamental importância, uma vez que a dosagem de peróxido de hidrogênio pode ser correlacionada com a eficiência global de degradação, enquanto que a concentração de ferro comanda aspectos cinéticos do processo..$^{43}$ Entretanto, o excesso de ambos os reagentes pode comprometer a degradação dos contaminantes, uma vez que $\mathrm{H}_{2} \mathrm{O}_{2}$ e $\mathrm{Fe}^{2+}$ podem agir como sequestrantes de radical $\mathrm{OH} \bullet$, prejudicando a eficácia do processo. ${ }^{23,44}$

Quando aplicados no solo, os processos Fenton requerem maiores quantidades de peróxido de hidrogênio para garantir a mineralização dos poluentes, em razão de alguns componentes do solo (ex. matéria orgânica) consumirem peróxido em reações paralelas ou participarem em reações de seqüestro de espécies radicalares. ${ }^{45}$ Assim, peróxido de hidrogênio é aplicado em elevadas concentrações, usualmente de 2 a $12 \%$, o que garante maiores taxas de degradação em função da formação de várias espécies ativas que contribuem com a mineralização do contaminante, ${ }^{22}$ incluindo radical superóxido $\left(\mathrm{O}_{2}{ }^{--}\right)$, radical hidroperoxila $\left(\mathrm{HO}_{2}{ }^{\circ}\right)$ e o ânion hidroperóxido $\left(\mathrm{HO}_{2}^{-}\right)$.

Petigara e colaboradores ${ }^{46}$ estudaram a decomposição de peróxido de hidrogênio em solos e a consequente formação de radicais hidroxila. Os autores observam que em solos com elevado teor de matéria orgânica a concentração de peróxido de hidrogênio decai rapidamente, em função de reações que não são produtivas em relação à geração de radical hidroxila. Assim, foi estimado que somente $10 \%$ do peróxido é decomposto para a formação de radicais hidroxila. Diferentemente, a decomposição do peróxido de hidrogênio em solos com baixo teor de matéria orgânica é lenta, o que favorece a formação de radical hidroxila.
Adicionalmente, a matéria orgânica pode adsorver os contaminantes, diminuindo o acesso à ação do radical hidroxila, e, consequentemente, impedindo as reações de oxidação. Assim, solos que apresentam menor teor de matéria orgânica podem ser tratados de forma mais eficiente, em comparação a solos com maior teor. ${ }^{47}$

Em solos com alto teor de carbonato a eficiência da degradação também é comprometida, porque os íons carbonato reagem com os radicais hidroxila, impedindo a oxidação do contaminante. ${ }^{3}$ Esta característica, típica de solos calcários, apresenta um inconveniente adicional, representado pelas dificuldades encontradas para diminuir o $\mathrm{pH}$ e favorecer o processo Fenton convencional. Nestes casos, entretanto, os processos podem ser aplicados na presença de quelatos de ferro, usualmente envolvendo o uso de ácido etilenodiamino tetra-acético (EDTA), ácido nitriloacético (NTA), ácido oxálico e ácido tartárico, o que permite eficiente degradação até em valores de $\mathrm{pH}$ próximos à neutralidade.

Em função da clara relação existente entre a eficiência do processo Fenton e as características do solo contaminado, a necessidade de estudos de tratabilidade é evidente. De acordo com observações do ICTR (Interstate Technology \& Regulatory Council, EUA), ${ }^{48}$ a realização de estudos em escala de laboratório é de fundamental importância para garantir a eficácia dos processos em larga escala, principalmente em sistemas de tratamento in-situ fundamentados no uso de oxidantes químicos. Dentro deste contexto se recomenda a realização de ensaios em escala piloto no próprio sitio contaminado (on-site), de maneira a permitir o desenho de um sistema de injeção de agentes químicos que assegure uma distribuição uniforme no local contaminado, o desenho de um sistema de amostragem que permita avaliar a dispersão dos oxidantes e a eficiência do tratamento nas três dimensões e a implementação de um sistema de monitoramento da água subterrânea.

\section{Impactos causados no solo por processos Fenton}

Como comentado anteriormente, a aplicação dos processos Fenton em solos requer elevadas concentrações de peróxido de hidrogênio, o que irremediavelmente acaba provocando impactos negativos na qualidade de solo. Dentre os impactos mais evidentes é possível destacar a destruição da matéria orgânica, a solubilização de metais e a morte dos micro-organismos presentes no solo.

Diversos autores relatam o efeito dos processos Fenton na degradação da matéria orgânica. De acordo com observações de Bissey, Smith e Watts, ${ }^{49}$ a destruição da matéria orgânica pelo processo Fenton é dependente do $\mathrm{pH}$, sendo praticamente irrelevante em meio neutro. Resultado similar foi observado por Wang e colaboradores, ${ }^{50}$ que avaliaram a degradação da matéria orgânica em função da concentração de peróxido de hidrogênio. Neste caso, foi observado que a degradação é proporcional à concentração de peróxido, sem, no entanto, ultrapassar taxas de degradação da ordem de $20 \%$. Em

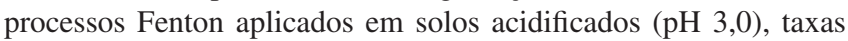
de degradação de matéria orgânica de até $80 \%$ foram observadas. ${ }^{51}$

As elevadas concentrações de peróxido de hidrogênio aplicadas na remediação do solo favorecem a formação de outras espécies radicalares, como radical superóxido $\left(\mathrm{O}_{2} \bullet\right)$ e hidroperoxila $\left(\mathrm{HO}_{2} \bullet\right), \mathrm{o}$ que pode favorecer a dissolução de metais. De acordo com Monahan e colaboradores,${ }^{52} \mathrm{o}$ radical superóxido pode provocar a redução dos metais, promovendo a sua dissolução e lixiviação para os corpos hídricos, o que pode impossibilitar o uso da mesma para abastecimento público. Além disso, a degradação da matéria orgânica no solo também pode promover a solubilização dos metais a ela associada.

A aplicação de processos Fenton também pode causar a morte dos micro-organismos presentes no solo. Em estudo realizado por Fergusson e colaboradores ${ }^{53}$ foi observada uma redução da flora 
microbiana até níveis não detectáveis, por conta da aplicação de processos Fenton durante três dias. De acordo com os autores, a destruição de flora microbiana pode ter sido causada pelas fortes condições oxidantes, pela elevação da temperatura (por ser um processo exotérmico) ou pela requerida diminuição do $\mathrm{pH}$ para maior eficiência no processo de degradação.

Adicionalmente, Sirguei e colaboradores ${ }^{54}$ avaliaram a toxicidade de solos submetidos à remediação por Processos Fenton, utilizando bioensaio fundamentado na germinação de sementes de azevém. Os resultados mostraram que a germinação não foi comprometida no solo submetido ao tratamento Fenton. Resultados similares foram relatados por Pardo e colaboradores, ${ }^{55} \mathrm{em}$ estudos de toxicidade fundamentados no uso de Vibrio fischeri no resíduo aquoso formado após o tratamento de um solo contaminado com etilbenzeno.

Laurent e colaboradores ${ }^{56}$ observaram que após o tratamento Fenton a fertilidade do solo foi afetada, principalmente em função da diminuição do $\mathrm{pH}$ que acaba prejudicando o crescimento das plantas. Outro efeito observado foi a diminuição da capacidade de troca catiônica do solo, a qual está ligada diretamente com a disposição de íons que são essenciais para a fertilidade do solo.

A aplicação dos processos Fenton também pode favorecer a lixiviação dos contaminantes e dos subprodutos formados. De acordo com Watts e colaboradores,$^{57}$ o processo de degradação no solo é comandado por processos de dessorção-oxidação. Desta forma, se a dessorção do contaminante ocorre mais rapidamente que a sua oxidação, a lixiviação destes compostos para os corpos hídricos é favorecida.

A Figura 4 ilustra os principais processos que podem ser esperados em um solo contaminado submetido a processos Fenton. Inicialmente (A), o contaminante entra em contato com a matriz de solo, interagindo de forma que depende da sua natureza e da própria natureza do solo. Em geral, espécies mais hidrofílicas podem ser lixiviadas, enquanto que espécies mais hidrofóbicas podem ser retidas por sorção. Os contaminantes também podem ser degradados pela flora microbiana, com a formação de subprodutos que lixiviam ou ficam retidos, de acordo com a sua natureza. Durante a remediação por processos Fenton (B), espécies radicalares muito reativas são formadas, o que poderá permitir a degradação dos poluentes retidos no solo. Em um processo ideal (C), o substrato será degradado formando subprodutos de menor toxicidade, que poderão lixiviar sem grande risco, ou de maior toxicidade, que poderão ser retidos por sorção. Em uma condição menos favorável (D), o processo Fenton pode degradar parcialmente os poluentes do solo, produzindo subprodutos de maior toxicidade que lixiviam. Adicionalmente, a matéria orgânica natural pode ser degradada, e as formas minerais do solo podem ser dissolvidas, o que pode implicar na desestruturação do solo e na lixiviação de íons metálicos.

Adicionalmente, é importante salientar que a reação Fenton pode ser fortemente exotérmica, principalmente com o uso de $\mathrm{H}_{2} \mathrm{O}_{2}$ em concentrações superiores a $10 \%,{ }^{58}$ o que provoca significativo aumento da temperatura, violenta liberação de gás e eventual liberação de compostos voláteis.

Por outro lado, é também importante mencionar que o peróxido de hidrogênio é classificado como produto "perigoso", principalmente em função das suas propriedades corrosivas, o que obriga a implementação de boas práticas de transporte, manuseio e armazenagem.

Embora os processos sejam tão complexos quanto os da química radicalar e da própria matriz de solo, estima-se que os processos Fenton permitam uma boa relação custo/benefício, o que faz com que esta tecnologia de remediação venha sendo cada vez mais utilizada em processos de remediação de solos. No entanto, é importante salientar que a eficiência do processo, os mecanismos de degradação envolvidos e o seu impacto no solo são absolutamente dependentes das características da matriz de solo e das condições em que o processo Fenton é aplicado, o que torna imprescindível a realização de estudos que permitam elucidar este tipo de relação.

\section{Tratamento Fenton de solos brasileiros}

De acordo com o Sistema Brasileiro de Classificação de Solos existem aproximadamente treze tipos de solos no Brasil, incluindo latossolos argilosos ricos em minerais de ferro e espodossolos
(A) CONTAMINANTE

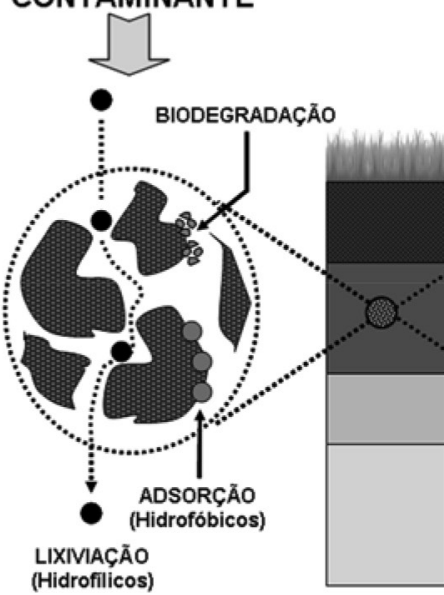

(B) FENTON

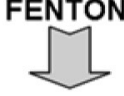

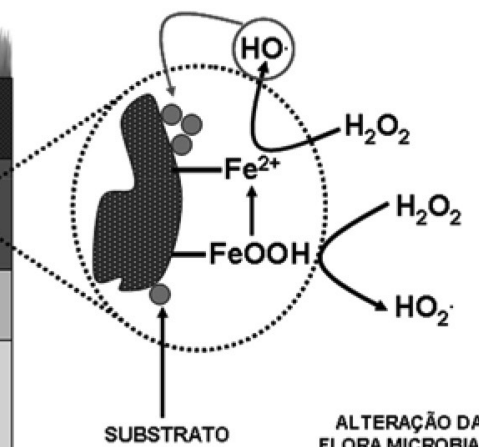

PRODUTOS DE
DEGRADAÇÃO DEGRADAÇÁO
(Inócuo) (Tóxico)
(T)

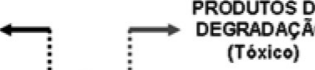


arenosos com baixo teor de ferro e, em alguns casos, com elevada concentração de matéria orgânica. Em função da já comentada forte relação existente entre a eficiência/impacto do tratamento Fenton e as principais características do solo, é fácil imaginar que a grande diversidade de solos do território brasileiro impeça o estabelecimento de uma fórmula genérica de tratamento.

Até onde foi possível investigar, poucos trabalhos foram publicados acerca do tratamento de solos brasileiros por processos Fenton, apesar da técnica já ser oferecida comercialmente como alternativa de remediação. Grande parte destes trabalhos envolve o uso de latossolos, o que se mostra coerente, em razão deste tipo de solo representar aproximadamente $60 \%$ do território brasileiro e da região Amazônica. ${ }^{59}$

Pereira e colaboradores, ${ }^{34}$ por exemplo, avaliaram a degradação de HPAs em um latossolo vermelho por processos Fenton. Em função da elevada concentração de ferro nativo $\left(258 \mathrm{~g} \mathrm{~kg}^{-1}\right)$, representada principalmente por hematita e goetita, o processo mostrou elevada eficiência de degradação, sem a necessidade de suplementação com formas solúveis de ferro. Entretanto, a cinética menos favorecida dos processos mediados por óxidos de ferro faz com que sejam necessários tempos de reação significativamente maiores aos praticados em processos catalisados por ferro solúvel. Por sua vez, Villa e colaboradores ${ }^{51}$ avaliaram a degradação de diesel em um solo franco, contendo concentrações equivalentes de areia (41\%) e silte (47\%), assim como baixa concentração de argila (12\%). Aplicando o tratamento na forma de lama ( $\mathrm{pH} 3$ ) foi observada a degradação de aproximadamente $80 \%$ da concentração inicial de diesel, utilizando elevadas concentrações de $\mathrm{FeSO}_{4}\left(12 \mathrm{mmol} \mathrm{L}^{-1}\right)$ e $\mathrm{H}_{2} \mathrm{O}_{2}$ (7-10 mol $\left.\mathrm{L}^{-1}\right)$. Nestas condições também foi observada importante degradação da matéria orgânica do solo (aproximadamente 80\%), assim como a lixiviação de metais (ex. $\mathrm{Zn}$ e $\mathrm{Cu}$ ).

\section{CONSIDERAÇÕES FINAIS}

Em razão da favorável relação custo/benefício, os processos Fenton vêm sendo rotineiramente utilizados na remediação de solos contaminados, usualmente permitindo eficiente degradação de poluentes resistentes. Entretanto, a eficiência de degradação é dependente das características do solo e das condições em que o processo é aplicado, o que faz com que não existam fórmulas milagrosas passíveis de aplicação universal. Desta forma, cada aplicação deve ser precedida de uma adequada caracterização do sítio contaminado, de maneira a permitir a identificação e quantificação das formas minerais de ferro e a identificação de espécies químicas que prejudicam a eficiência do processo, consumindo peróxido de hidrogênio o sequestrando formas radicalares (ex. matéria orgânica e carbonatos).

Deste ponto de vista, a concentração de peróxido de hidrogênio representa um parâmetro crítico, do qual depende a eficiência e o impacto do processo Fenton. Em alguns casos a eficiência poderá ser melhorada com o aumento na concentração deste oxidante, enquanto em outros, o aumento da concentração poderá acarretar um evidente impacto no solo, sem significativas melhoras na eficiência do processo.

Assim, o processo Fenton representa uma excelente alternativa para remediação de solos contaminados, desde que as condições de tratamento sejam compatíveis com as principais características do solo em questão.

\section{REFERENCIAS}

1. Guo, H.; Yao, J.; Cai, M.; Qian, Y.; Guo, Y.; Richnow, H.; Blake, R.; Doni, S.; Ceccanti, B.; Chemosphere 2012, 87, 1273.

2. Neyens, E.; Baeyens, J.; J. Hazard. Mater. 2003, 98, 33.
3. Watts, R. J. M.; Teel, A.; J. Environ. Eng. 2005, 131, 612.

4. Andrade, J. A.; Augusto, F.; Jardim, I. C. S.; Ecl. Quím. 2010, 35, 17.

5. Paria, S.; Adv. Colloid Int. Sci. 2008, 138, 24.

6. Watts, R. J.; Haller, D. R.; Jones, A. P.; Teel, A. L.; J. Hazard. Mater. 2000, 76, 73 .

7. Corseuil, H. X.; Marins, M. D.; Eng. Sanit. Ambiental 1997, 2, 50.

8. Österreicher-Cunha, P.; Vargas Jr, E. A.; Guimarães, J. R. D, Lago, G. P.; Antunes, F. S.; Silva, M. I. P.; Int. Biodeterior. Biodegrad. 2009, 2, 208.

9. Guedes, C. L.; Correr, C. J.; Lobo, I.; Abi-Saab, O. J. G.; Revista Semina: Ciências Exatas e Tecnológicas 2010, 31, 87.

10. Reddy, K. R.; Geotechnical and Geological Engineering 2010, 28, 211.

11. Chien, Y.; J. Hazard. Mater. 2012, 199-200, 457.

12. Lin, T. C; Pan, P. T.; Cheng, S. S.; J. Hazard. Mater. 2010, 176, 27.

13. Falciglia, P. P.; Giustra M. G.; Vagliasindi, F. G. A.; J. Hazard. Mater. 2011, 185, 392.

14. Uhmann, A.; Aspray.T. J.; J. Hazard. Mater. 2012, 219, 141.

15. Ferrarese, E.; Andreottola, G.; Oprea, I. A.; J. Hazard. Mater. 2008, 152, 128.

16. Albergaria, J. T.; Alvim-Ferraz, M. C.; Delerue-Mato, C.; J. Environ. Manage. 2012, 104, 195.

17. Johnston, C. D.; Rayner, J. L.; Briegel, D.; J. Contam. Hydrol. 2002, 59, 87.

18. Sarkar, D.; Ferguson, M.; Datta, R.; Birnbaum, S.; J. Environ. Pollut. 2005, 136, 187.

19. Zacarias-Salinas, M.; Vaca, M.; Flores, M. A.; Bandala, E. R.; Torres, L. G.; J. Environ. Prot. 2013, 4, 1495.

20. Yen, C.; Chen, K.; Kao, C.; Liang, S.; Chen, T.; J. Hazard. Mater. 2011, 186, 2097.

21. Andreozzi, R.; Caprio, V.; Insola, A.; Marotta, R.; J. Catal. Today 1999, 53,51 .

22. Neyens, E.; Baeyens, J.; J. Hazard. Mater. 2003, 98, 33.

23. Walling, C. H.; Acc. Chem. Res. 1975, 8, 125.

24. Aguiar, A.; Ferraz, A.; Contreras, D.; Rodriguez, J.; Quím. Nova 2007, 30,623 .

25. Walling, C.; Goosen, A.; J. Am. Chem. Soc. 1973, 95, 2987.

26. Watts, R. J.; Udell, M. D.; Rauch, P. A.; Hazard. Waste Hazard. Mater. 1990, 7, 335 .

27. Villa, R. D.; Trovó, A. G.; Nogueira, R. F. P.; J. Braz. Chem. Soc. 2010, $21,1088$.

28. Xu, P.; Achari, G.; Mahmoud, M.; Joshi, R. C.; Pract. Period. Hazard., Toxic, Radioact. Waste Manage.2006, 10, 19.

29. Oliveira, A. O.; Fabris, J. D.; Pereira, M. C.; Quím. Nova 2013, 36, 123.

30. Watts, R. J.; Udell, M. D.; Kong, S.; Leung, S.; Environ. Eng. Sci. 1999, 16,93 .

31. Tyre, B. W.; Watts, R. J.; Miller, G. C.; J. Environ. Quality 1991, 20, 832.

32. Garrido-Ramírez, E. G.; Theng, B. K. G.; Mora, M. L.; Appl. Clay Sci. 2010, 47, 182.

33. Watts, R. J.; Stanton, P. C.; Howsawkeng, J.; Teel, A. L.; Water Res. 2002, 36, 4283.

34. Pereira, C. A.; Marques M. R. C.; Pérez, D. V.; Quím. Nova 2009, 32, 2200.

35. Romero, A.; Santos, A.; Vicente, F.; Rodriguez, S.; Lopez, A. L.; J. Hazard. Mater. 2009, 170, 627.

36. Haber, F.; Weiss, J.; Proc. Royal Soc. London 1934, 147, 332.

37. Lin, S. S.; Gurol, M. D.; Environ. Sci.Technol. 1998, 32, 1417.

38. Prucek, R.; Hermanek, M.; Zboril, R.; Appl. Catal. A 2009, 366, 325.

39. Khan, A. J.; Watts, R. J.; Water, Air, Soil Pollut. 1996, 88, 247.

40. Chou, S. S.; Huang, C. P.; Chemosphere 1998, 38, 2719.

41. Chen, P.; Watts, R.; J. Chin. Inst. Environ. Eng. 2000, 10, 201.

42. Teel, A. L.; Warberg, C. R.; Atkinson, D. A.; Watts, R. J.; Water Res. 2001, 35, 977

43. Chamarro, E.; Marco, A.; Esplugas, S.; Water Res. 2001, 35, 1047. 
44. Narayanan, T. S. N.; Magesh, G.; Rajendran, N.; Fresenius Environ Bull. 2003, 12, 776.

45. Romero, A; Santos, A.; Cordero,T.; Rodríguez-Mirasol, J.; Rosas, J. M.; Vicente, F.; Chem. Eng. J. 2011, 170, 36.

46. Petigara, B. R.; Blough, N. V; Mignerey, A. C.; Environ. Sci. Technol. 2002, 36, 639 .

47. Venny; Gan, S.; Kiat, N. H.; Chem. Eng. J. 2012, 213, 295.

48. In Situ Chemical Oxidation Team; Technical and Regulatory Guidance for In Situ Chemical Oxidation of Contaminated Soil and Groundwater, $2^{\text {nd }}$ ed., 2005, ISCO-2, Interstate Technology \& Regulatory Council: Washington, D. C., 2005 Available on the internet at http://www.itrcweb. org.

49. Bissey, L. L.; Smith, J. L.; Watts, R. J.; Water Res. 2007, 40, 2477.

50. Wang, W.; Xu, J.; Huang, F.; Cui, Y.; Toxicol. Environ. Chem. 2015, 97, 275.

51. Villa, R.D.; Trovó, A. G.; Nogueira, R. F. P.; Chemosphere 2008, 71, 43.
52. Monaham, M. J.; Teel, A. L.; Watts, R. J.; Water Res.2005, 39, 2955.

53. Ferguson, S. H.; Woinarski, A. Z.; Snape, I.; Morris, C. E.; Revill, A. T.; Cold Reg. Sci. Technol. 2004, 40, 47.

54. Sirguey, C.; Souza e Silva, P. T.; Schwartz, C.; Simonnot, M.; Chemosphere 2008, 72, 282.

55. Pardo, F.; Rosas, J. M.; Santos, A.; Romero, A.; J. Chem. Technol. Biotechnol. 2015, 90, 754 .

56. Laurent, F.; Cebron, A.; Schwartz, C.; Leyval, C.; Chemosphere 2012, 86,659 .

57. Watts, R. J.; Kong, S.; Dippre, M.; Barnes, W. T.; J. Hazard. Mater. 1994, 39, 33.

58. Mater, L.; Rosa, E. V. C.; Berto, J.; Correa, A. X. R.; Schwingel, P. R; Radetski, C. M.; J. Hazard. Mater. 2007, 149, 386.

59. Coelho, M. R.; Fidalgo, E. C.; Santos, H. G.; Brefin, M. L. M.; Pérez, D. V. Em O ecossistema solo; Moreira, F. M. S., Cares, J. E., Zanetti, R., Stürmer, S. L., eds.; Editora UFLA: Lavras, 2013, cap. 3. 